\title{
Editorial \\ Commentary on the Special Issue, Systems for Systems: Computational Systems Modeling to Promote Equity and Access in K12 STEM Educational Systems
}

\author{
Okhee Lee
}

Citation: Lee, O. Commentary on the Special Issue, Systems for Systems: Computational Systems Modeling to Promote Equity and Access in K12 STEM Educational Systems. Systems 2021, 9, 30. https://doi.org/ 10.3390 /systems 9020030

Received: 9 April 2021

Accepted: 15 April 2021

Published: 22 April 2021

Publisher's Note: MDPI stays neutral with regard to jurisdictional claims in published maps and institutional affiliations.

Copyright: (C) 2021 by the author. Licensee MDPI, Basel, Switzerland. This article is an open access article distributed under the terms and conditions of the Creative Commons Attribution (CC BY) license (https:// creativecommons.org/licenses/by/ $4.0 /)$.
Department of Teaching and Learning, Steinhardt School of Culture, Education, and Human Development, New York University, New York, NY 10003, USA; olee@nyu.edu

The dual goal of this Special Issue is to highlight the implementation of computational systems modeling tools for K12 science teachers and students and to address equity and access for student groups who have historically been left out of mainstream research on computational systems modeling. This Special Issue illustrates innovative research programs that focus on this dual goal-computational systems modeling for all students. This Special Issue is timely, as computational systems modeling is increasingly in demand to help all students explain complex phenomena and design solutions to complex societal problems.

The four articles in the Special Issue describe in rich detail how their research projects promoted equity and access to computational systems modeling for all students. The four articles address computational systems modeling from different conceptual perspectives, across varied educational contexts, and with diverse teacher and student groups. With regard to conceptual perspectives, the articles present a comprehensive picture of the research programs on computational systems modeling. With regard to educational contexts, the articles describe how computational systems modeling tools can be implemented across K12 grade levels and across formal and informal settings (e.g., an ecology center). With regard to equity, whereas certain student groups were traditionally deemed unable to participate in computational systems modeling, the articles provide convincing evidence that diverse student groups capitalize on affordances of computational systems modeling to learn academic disciplines, such as science. Collectively, this Special Issue presents computational systems modeling from different conceptual perspectives, across varied educational contexts, and with diverse teacher and student groups to represent the current state of the research as well as spotlight what lies ahead if computational systems modeling is to be used to help all learners succeed.

In this commentary, the articles in the Special Issue are synthesized and a description is provided about how they contribute to furthering the field [1]. This commentary also relates how this research on computational systems modeling promotes equity and aligns with the new administration's priorities, which place science and equity at the core.

First, considering the complexities in any given system, a systems approach to studying or designing an intervention must include the consideration of multiple conceptual perspectives. The four articles in this Special Issue employ a range of conceptual perspectives to investigate computational systems modeling. Haas et al. [2] integrate systems thinking from the perspectives of science education and computer science education, with a focus on English learners. Pierson and Brady [3] integrate computational and embodied modeling with multimodal and everyday resources that English learners bring to the science classroom. Cottone et al. [4] integrate data literacy and model-based learning through the usability cube framework for educational reform. Marei et al. [5] integrate an online feedback facilitation system with asynchronous teacher professional development. Collectively, the four articles illustrate a rich array of conceptual perspectives on computational systems modeling. 
Second, this Special Issue addresses systems broadly as learners (students or teachers) interact with computational systems modeling at the individual level or the system level (e.g., a school district). All learners bring varying resources (e.g., cultural resources, linguistic resources) and need varying types of support in the education system (e.g., a high-quality curriculum for English learners). The four articles address computational systems modeling across varied educational settings. Haas et al. [2], Pierson and Brady [3], and Cottone et al. [4] used the Starlogo Nova computational model platform in different educational contexts. Haas et al. [2] investigate how computational modeling promotes systems thinking with English learners in one fifth-grade science classroom. Pierson and Brady [3] investigate how embodied modeling (role-playing agents in a system) supports science learning with English learners in one middle school classroom. Cottone et al. [4] investigate the participation and engagement of all fourth- and fifth-grade students and their teachers in an urban school district. In an online asynchronous professional development course, Marei et al. [5] investigate how an online feedback facilitation system influenced high school teachers' learning. Collectively, the four articles investigate computational systems modeling with both students and teachers from elementary school through high school, from classrooms to a school district, and within a teacher professional development course.

A system is composed of subsystems at multiple levels of scale, and each subsystem has multiple components at each level. The components of each system interact, resulting in changes in the system over time. An intervention is intended to bring out the intended changes in the system at one level, which could trigger both intended and unintended changes at other levels [6]. The four studies in this Special Issue investigate the implementation and outcomes of educational interventions. Haas et al. [2] investigate an elementary science curriculum with a focus on English learners. Pierson and Brady [3] investigate collaboration between a researcher and a middle school teacher to iteratively design, implement, and refine embodied modeling activities with a focus on English learners. Cottone et al. [4] investigate a districtwide reform with elementary teachers and students. Marei et al. [5] investigate an online feedback facilitation system in an online asynchronous professional development course. Collectively, the four articles investigate the design, implementation, and impact of educational interventions to bring out desired changes at various levels of the education system.

Third, computational thinking has become prominent in educational systems, especially in STEM subjects [7]. Yet, "few studies have examined instructional materials that enable teachers of STEM subjects to support ELs in developing computational thinking" [8]. Three articles in this Special Issue directly address equity and access to computational systems modeling, with a focus on English learners [2,3] and students from low socioeconomic backgrounds [4].

Haas et al. [2] and Pierson and Brady [3] focus on English learners, a fast-growing student population in the nation. Traditional approaches with English learners often implemented pull-out programs until students developed sufficient vocabulary and grammar to be integrated into content area classrooms. In addition, traditional approaches frontloaded or pretaught vocabulary as a prerequisite or precursor to content learning. Contemporary approaches, in contrast, engage English learners in content learning regardless their English language proficiency [8]. In the science classroom, as English learners "do" science, they use language and develop language as a product of doing science. Haas et al. [2] and Pierson and Brady [3] engage English learners in computational modeling in service of learning science. Based on the contemporary asset-oriented approach, both articles highlight affordances of computational modeling to make sense of local phenomena, such as garbage [2] and ecosystems [3]. Provided with rich contexts for fostering systems thinking, English learners were able to use computational modeling to communicate their science ideas. Both articles describe how English learners used multiple modalities (including embodiment and gestures) and less-then-perfect English to communicate their science ideas. Moreover, both articles emphasize that the use of nonlinguistic modalities, including embodiment and 
gesture, was "not merely a scaffold or crutch, as nonlinguistic modalities have traditionally been conceived in the literature on teaching ELs. Instead, multiple modalities are essential to engaging in systems thinking practices while also being beneficial to ELs" [2]. Together, these two articles identify affordances of nonlinguistic modalities for English learners to engage in systems thinking, despite their less-than-perfect English.

Cottone et al. [4] worked with all fourth- and fifth-grade teachers in an urban school district where $99 \%$ of the students attending elementary schools received free or reducedprice lunch. Thus, the intervention served students who needed improved educational resources in STEM subjects. While the intervention was not intentionally designed to serve such students, it was overall successful in engaging students in inquiry, active learning, and data literacy skills. Cottone et al. [4] state "whether these positive student learning outcomes led to an increase in student interest in scientific inquiry or complex systems modeling was not assessed" (p. 15).

Finally, the four articles offer insights into the potential of computational modeling for fostering systems thinking with all students, which is in alignment with the new administration's seven immediate priorities (https:/ / www.whitehouse.gov/priorities/, accessed on 28 March 2021). The White House's priorities focus on science (i.e., COVID19, climate, and health care) and equity (i.e., racial equity and immigration) in order to ultimately bolster the economy and restore America's global standing. These seven priorities require systems thinking that involves convergence of multiple disciplines in addressing these societally complex problems. Unlike traditional approaches in which equity was often an afterthought or an accommodation after decisions had already been rendered, current national policies place equity and justice at the core. As described in the four articles in this Special Issue, computational systems modeling for all students has the potential to address complex societal phenomena and problems whose solutions require systems thinking through the convergence of multiple STEM disciplines [1].

Conflicts of Interest: The author declares no conflict of interest.

\section{References}

1. Yoon, S.A.; Goh, S.-E.; Park, M. Teaching and learning about complex systems in K-12 science education: A review of empirical studies 1995-2015. Rev. Educ. Res. 2018, 88, 285-325. [CrossRef]

2. Haas, A.; Grapin, S.E.; Wendel, D.; Llosa, L.; Lee, O. How fifth-grade English learners engage in systems thinking using computational models. Systems 2020, 8, 47. [CrossRef]

3. Pierson, A.E.; Brady, C.E. Expanding opportunities for systems thinking, conceptual learning, and participation through embodied and computational modeling. Systems 2020, 8, 48. [CrossRef]

4. Cottone, A.M.; Yoon, S.A.; Coulter, B.; Shim, J.; Carman, S. Building system capacity with a modeling-based inquiry program for elementary students: A case study. Systems 2021, 9, 9. [CrossRef]

5. Marei, A.; Yoon, S.A.; Yoo, J.-U.; Richman, T.; Noushad, N.; Miller, K.; Shim, J. Designing feedback systems: Examining a feedback approach to facilitation in an online asynchronous professional development course for high school science teachers. Systems 2021, 9, 10. [CrossRef]

6. National Research Council. A Framework for K-12 Science Education: Practices, Crosscutting Concepts, and Core Ideas; National Academies Press: Washington, DC, USA, 2012.

7. Weintrop, D.; Beheshti, E.; Horn, M.; Orton, K.; Jona, K.; Trouille, L.; Wilensky, U. Defining computational thinking for mathematics and science classrooms. J. Sci. Educ. Technol. 2016, 25, 127-147. [CrossRef]

8. National Academies of Sciences, Engineering, and Medicine. English Learners in STEM Subjects: Transforming Classrooms, Schools, and Lives; National Academies Press: Washington, DC, USA, 2018; p. 70. 